The following pages constitute the final, accepted and revised manuscript of the article:

Nilsson, $\mathrm{M}$ and Panagopoulos, I and Mertens, F and Mandahl, N

"Fusion of the HMGA2 and NFIB genes in lipoma"

Virchows Arch. 2005 Nov;447(5):855-8.

Publisher: Springer.

Use of alternative location to go to the published version of the article requires journal subscription.

Alternative location: http://dx.doi.org/10.1007/s00428-005-0037-9 


\title{
Fusion of the HMGA2 and NFIB genes in lipoma
}

\author{
M. Nilsson, I. Panagopoulos, F. Mertens, N. Mandahl
}

M. Nilsson, I. Panagopoulos, F. Mertens, N. Mandahl (corresponding author)

Department of Clinical Genetics, University Hospital, SE-221 85 Lund, Sweden

e-mail: nils.mandahl@med.lu.se

Tel: +46 46 173364, Fax: +46 46131061

Keywords: lipoma, HMGA2, NFIB, fusion gene 


\begin{abstract}
The major cytogenetic subgroup of lipomas is characterized by aberrations of chromosome segment 12q13-15, which recombines with a large number of other chromosomal regions. The gene HMGA2 is the main target in these aberrations. For some recurrent rearrangements, chimeric transcripts including the $5^{\prime}$ part of HMGA2 have been described. The $3^{\prime}$ partners identified are $L P P, L H F P, C M K O R 1$ and EBF. Also subsets of other benign solid tumors show aberrations of 12q13-15. Among pleomorphic adenomas of the salivary glands, where the preferred recombination partner with 12q13-15 is 9p22-24, a HMGA2/NFIB fusion gene has been reported. In the present study, two cases of lipoma with rearrangements of 9p22-24 and 12q15 were analyzed by RT-PCR to find out if HMGA2/NFIB is present also in lipoma. An in frame fusion transcript, combining the four first exons of HMGA2 with exon 8 of NFIB, was detected in one case. It was identical to a transcript previously described in salivary gland adenoma, and contained a stop codon shortly 3' of the fusion point. The finding of the same fusion gene in different tumors is not unique. For example, HMGA2/LPP has been reported in lipoma, pulmonary chondroid hamartoma and soft tissue chondroma. Since similar 9;12translocations have been described also in rare cases of hamartoma and uterine leiomyoma, the occurrence of HMGA2/NFIB could be postulated in these tumors as well.
\end{abstract}




\section{Introduction}

Several benign solid tumor entities are characterized cytogenetically by rearrangements of the chromosome segment 12q13-15 [e.g., 3, 7, 8, 11, 17]. The fraction of tumors displaying aberrations of this segment ranges from about $60 \%$ among lipomas and chondroid hamartomas of the lung, to 30-35\% of uterine leiomyomas and hemangiopericytomas and 20-25\% of pleomorphic adenomas of the salivary glands and chondromas [13]. Typically, 12q13-15 recombines with a large variety of other chromosome bands through translocations, insertions and inversions. Although almost any band may be involved, there are some cytogenetically identical changes that have been detected in several cases. These recurrent aberrations may vary from one tumor type to another. Among lipomas, the preferred rearrangement t(3;12)(q27-28;q13-15) is present in every fifth tumor with involvement of 12q14-15 [14].

The gene HMGA2 (previously HMGIC), located in 12q14-15, is the central molecular target of these chromosomal aberrations and plays an essential role for the tumorigenesis of these lesions $[1,4]$. The breakpoints related to the structural chromosome aberrations may be located within the gene or at megabase distances outside the gene and the effects may be dysregulation of gene expression, truncation of the gene or the formation of a fusion gene encoding a chimeric transcript. Among lipomas, HMGA2 has been reported to form fusion genes with CMKOR1 (in 2q35-37), LPP (in 3q27-28), EBF (in 5q33) and LHFP (in 13q12) [2, 15, 18, 19]. The HMGA2/LPP chimera has also been described in chondroid hamartomas [20] and in one case of soft tissue chondroma [3].

Among pleomorphic adenomas of the salivary gland the major cytogenetic subgroup is characterized by aberrations of $8 q 12$, whereas a minor subgroup shows rearrangements of 12q13-15. The dominating aberration is $\mathrm{t}(3 ; 8)$, but both $8 \mathrm{q} 12$ and $12 \mathrm{q} 13-15$ have been found 
to recombine with 9p22-24 in several cases. In two tumors, the recombination between 9p and 12q segments was demonstrated to result in the formation of a HMGA2/NFIB fusion gene [5]. In the present study, two cases of lipoma with recombination between 9p and 12q were investigated by RT-PCR to find out whether a HMGA2/NFIB chimera may be present also in this tumor type.

\section{Material and methods}

Two cases of lipoma with rearrangements affecting 9p22-24 and 12q15, as determined by Gband karyotyping, were available for RT-PCR analyses (Table 1).

Culturing, harvesting and chromosome banding of the tumor cells were as previously described [11]. In brief, the tumor tissue was disaggregated mechanically and then enzymatically, by 3-5 h treatment with collagenase II. The resulting cell suspension was rinsed with medium, to remove released fat, and distributed to glass chamber slides and flasks. RPMI 1640 medium with HEPES buffer, supplemented with 17\% fetal bovine serum, L-glutamine, penicillin and streptomycin, was then added to the cell suspension. G-banding of the chromosomes was obtained using Wright's stain solution. Karyotypic descriptions were according to ISCN (1995) [13].

Total RNA from frozen lipoma tissue kept at $-80^{\circ} \mathrm{C}$ was isolated using the RNeasy lipid tissue Mini Kit (Qiagen) according to the manufacturer’s instructions. From $5 \mu \mathrm{g}$ of total RNA, cDNA was synthesized by reverse transcription in a $20 \mu \mathrm{l}$ reaction, containing $50 \mathrm{mM}$ Tris-HCl, pH 8.3, $75 \mathrm{mM} \mathrm{KCl,} 3$ mM MgCl $2,10 \mathrm{mM}$ dithiothreitol, $1 \mathrm{mM}$ of each dNTP, 0.5 pM random hexamers, 28 U RNase inhibitor (RNA guard, Amersham), and 400 U M-MLV reverse transcriptase (Invitrogen). The reaction mix was incubated at $37^{\circ} \mathrm{C}$ for $1 \mathrm{~h}$, followed by $5 \mathrm{~min}$ at $65^{\circ} \mathrm{C}$. From each case, $1 \mu \mathrm{l}$ cDNA was amplified by PCR. ABL1-specific primers were used as a quality control [16]. 
All RT-PCR reactions were carried out in final volumes of $50 \mu \mathrm{l}$ containing $20 \mathrm{mM}$ Tris-HCl, pH 8.3, 50 mM KCl, 1.25 mM $\mathrm{MgCl}_{2}$, 0.2 mM of each dNTP, 1 U PlatinumTaq polymerase (Invitrogen), $0.5 \mu \mathrm{M}$ of each of the forward and reverse primers for HMGA2 and NFIB (Table 2) and $1 \mu \mathrm{l}$ of single-stranded cDNA, as a template. In a second PCR with the inner primers, $2 \mu \mathrm{l}$ of the PCR product were reamplified. The PCR was run on a PCT-200 DNA Engine (MJ Research). After the initial denaturation for 5 min at $95{ }^{\circ} \mathrm{C}, 30$ amplification cycles were performed, each consisting of denaturation for 1 min at $95{ }^{\circ} \mathrm{C}$, annealing for 1 min at $60{ }^{\circ} \mathrm{C}$, and extension for $1 \mathrm{~min}$ at $72{ }^{\circ} \mathrm{C}$. The PCR was completed by a final extension at $72{ }^{\circ} \mathrm{C}$ for 5 min.

The PCR products were analyzed on a $1.3 \%$ agarose gel, purified using the Qiagen gel extraction kit, and directly sequenced using the ABI Prism BigDye terminator v1.1 cycle sequencing kit (Applied Biosystems) on the Applied Biosystems Model 3100-Avant DNA sequencing system. Primers used for sequencing are listed in Table 2. For computer analyses of sequence data, BLAST software (http://www.ncbi.nlm.nih.gov/BLAST/) was used.

\section{Results}

G-banding revealed that case 1 had chromosome 12 material inserted into chromosome 9 as the sole anomaly in one clone, whereas the dominating clone had an additional copy of the derivative chromosome 9 (Table1). All three samples of the lobulated tumor of case 2 had a balanced translocation between chromosomes 9 and 12. The breakpoints in chromosome 9 were interpreted as 9p24 and 9p22, respectively, whereas both cases had a break in 12q15.

RT-PCR products obtained with forward primers for HMGA2 (HMG846 and HMG876) and reverse primers for NFIB (NF41475-006 and NF41475-005) revealed the presence of a HMGA2/NFIB gene fusion in case 2. The size of the HMGA2/NFIB product was approximately 400 bp. Its reciprocal counterpart, NFIB/HMGA2, was not detected. 
The amplified products were analyzed by direct sequencing (Fig. 1). Computer analyses of the sequence data, using BLAST software, showed that the fusion of the HMGA2/NFIB chimeric sequences was in frame and contained the first four exons of HMGA2 located $5^{\prime}$ to exon 8, the last coding exon of NFIB. The sixth codon of NFIB is a stop codon.

Expression of NFIB was detected in both cases, using forward primer NF41475-001 with reverse primers NF41475-006 and NF41475-005 (Table 2). Also HMGA2 was expressed in both cases as shown by forward primer HMG902 combined with reverse primers HMG1037 and HMG1144 to detect transcripts from exons 1-3 and exons 1-5, respectively.

\section{Discussion}

In one of the two presently investigated lipomas it was possible to demonstrate the presence of an HMGA2/NFIB fusion gene. Sequencing revealed that the resulting chimeric transcript was identical to that described previously in a case of salivary gland pleomorphic adenoma [6], i.e., combination of the four first exons of HMGA2 with exon 8 of NFIB. Although the fusion gene was in frame, the presence of a stop codon shortly 3' after the fusion point is compatible with the suggestion that the important outcome of the aberration is deregulation of the expression of the DNA binding 5' element of HMGA2 [1, 4, 5].

The $\mathrm{t}(9 ; 12)(\mathrm{p} 22-24 ; \mathrm{q} 13-15)$ has been reported not only in pleomorphic adenoma and lipoma but also in uterine leiomyoma and pulmonary chondroid hamartoma [6-8]. Aberrations involving 9p22-24, including $\mathrm{t}(9 ; 12)$, are more common among the adenomas and appear in about $9 \%$ of reported cases with chromosome aberrations, which is to be compared with $<2 \%$ in the three other tumor types [13]. The fraction of tumors with $t(9 ; 12)$ differs less, and ranges from below $1.5 \%$ among adenomas to less than $0.5 \%$ among leiomyomas. These four benign tumor types all include a cytogenetic subgroup characterized by rearrangements involving 12q13-15. Among these tumors, $\mathrm{t}(9 ; 12)(\mathrm{p} 22-24 ; \mathrm{q} 13-15)$ has been observed in about $1 \%$ of 
lipomas and hamartomas, in $4 \%$ of leiomyomas and in $10 \%$ of adenomas (Table 3). Several other aberrations including 12q13-15 are shared by two or more tumor types, but the frequencies may differ distinctly. Apart from the intrachromosomal rearrangements of chromosome 12, which are common among all four tumor types, only two segments, 9p22-24 and 14q22-24, have been involved in all of them, whereas several other rearrangements are shared by only two tumor types. With respect to the low resolution power of chromosome banding, similar cytogenetic rearrangements need not necessarily have the same consequences at the molecular level. However, the present findings, as well as previous findings of the presence of a HMGA2/LPP fusion genes in lipoma, hamartoma and chondroma, demonstrate that at least some of these shared cytogenetic aberrations are actually identical also at the molecular level. Since one and the same fusion gene may be associated with distinctly different tumor phenotypes, it seems reasonable to suggest that the aberrant gene might affect cell proliferation in an unspecific way, rather than being a determinant of tumor cell differentiation. The differences in frequencies of certain rearrangements among tumor types could then reflect the probability of a certain aberration to occur in a certain cell type. The mechanisms behind this remain unknown.

The present study provides yet another example of genetic aberrations that are shared by different tumor types. Based on these observations and available cytogenetic data, it seems reasonable to suggest that there are more shared aberrations to be found among benign solid tumors. More specifically, a HMGA2/NFIB fusion gene might be expected to occur also among leiomyomas and hamartomas.

Acknowledgements This work was supported by the Swedish Cancer Society. 


\section{References}

1. Ashar HR, Tkachenko A, Shah P, Chada K (2003) HMGA2 is expressed in an allelespecific manner in human lipomas. Cancer Genet Cytogenet 143:160-168

2. Broberg K, Zhang M, Strömbeck B, Isaksson M, Nilsson M, Mertens F, Mandahl N, Panagopoulos I (2002) Fusion of RDC1 with HMGA2 in lipomas as the result of chromosome aberrations involving 2q35-37 and 12q13-15. Int J Oncol 21:321-326

3. Dahlén A, Mertens F, Rydholm A, Brosjö O, Wejde J, Mandahl N, Panagopoulos I (2003) Fusion, disruption and expression of HMGA2 in bone and soft tissue chondromas. Mod Pathol 16:1132-1140

4. Fedele M, Battista S, Manfioletti G, Croce CM, Giancotti V, Fusco A (2001) Role of the hugh mobility group protein in human lipomas. Carcinogenesis 22:1583-1591

5. Geurts JMW, Schoenmakers EFPM, Röijer E, Aström A-K, Stenman G, van de Ven WJM (1998) Identification of NFIB as recurrent translocation partner gene of HMGIC in pleomorphic adenomas. Oncogene 16:865-872.

6. Kataoka Yamada H, Hoshi N, Kudo M, Hareyama H, Sakuragi N, Fujimoto S (2003) Cytogenetic analysis of uterine leiomyoma: the size, histopathology and GnRHaresponse in relation to chromosome karyotype. Eur J Obstet Gynecol Reprod Biol $110: 58-62$

7. Kazmierczak B, Meyer-Bolte K, Tran KH, Wockel W, Breightman I, Rosigkeit J, Bartnitzke S, Bullerdiek J (1999) A high frequency of tumors with rearrangements of genes of the HMGI(Y) family in a series of 191 pulmonary chondroid hamartomas. Genes Chromosomes Cancer 26:125-133

8. Kiechle-Schwarz M, Sreekantaiah C, Berger CS, Pedron S, Medchill MT, Surti U, Sandberg AA (1991) Nonrandom cytogenetic changes in leiomyomas of the female genitourinary tract. A report of 35 cases. Cancer Genet Cytogenet 53:125-136 
9. Mandahl N, Höglund M, Mertens F, Rydholm A, Willén H, Brosjö O, Mitelman F (1994) Cytogenetic aberrations in 188 benign and borderline adipose tissue tumors. Genes Chromosomes Cancer 9:207-215

10. Mandahl N (2001) Methods in solid tumor cytogenetics. In: Human Cytogenetics: Malignancy and Acquired Abnormalities. 3rd ed. Rooney DE. Ed. Oxford University Press, New York. pp. 165-203

11. Mark J, Dahlenfors R, Wedell B (1997) Impact of the in vitro technique used on the cytogenetic patterns in pleomorphic adenomas. Cancer Genet Cytogenet 95:9-15

12. Mitelman F (1995) ISCN (1995) An International System for Human Cytogenetic Nomenclature. S Karger, Basel, Switzerland

13. Mitelman Database of Chromosome Aberrations in Cancer. Mitelman F, Johansson B, Mertens F, Eds. http://cgap.nci.nih.gov/Chromosomes/Mitelman

14. Nielsen GP, Mandahl N (2002) Lipoma. In: World Health Organization Classification of Tumours. Pathology and Genetics of Tumours of Soft Tissue and Bone. Fletcher CDM, Unni KK, Mertens F, Eds. IARC Press, Lyon. pp. 19-46

15. Nilsson M, Mertens F, Höglund M, Mandahl N, Panagopoulos I (2005) Truncation and fusion of HMGA2 in lipomas with rearrangements of 5q32-33 and 12q14-15. Cytogenet Genome Res (in press)

16. Panagopoulos I, Mertens F, Domanski HA, Isaksson M, Brosjö O, Gustafson P, Mandahl N (2001) No EWS/FLI1 fusion transcripts in giant-cell tumors of bone. Int J Cancer 93:769-772

17. Pandis N, Heim S, Bardi G, Flodérus UM, Willén H, Mandahl N, Mitelman F (1991) Chromosome analysis of 96 uterine leiomyomas. Cancer Genet Cytogenet 55:11-18 
18. Petit MMR, Mols R, Schoenmakers EFPM, Mandahl N, Van de Ven WJM (1996) $L P P$, the preferred fusion partner gene of HMGIC in lipomas, is a novel member of the LIM protein gene family. Genomics 36:118-129

19. Petit MMR, Schoenmakers EFPM, Huysman C, Geurts JMW, Mandahl N, Van de Ven WJM (1999) LHFP, a novel translocation partner gene of HMGIC in a lipoma, is a member of a new family of LHFP-like genes. Genomics 57:438-441

20. Rogalla P, Lemke I, Kazmierczak B, Bullerdiek J (2000) An identical HMGIC-LPP fusion transcript is consistently expressed in pulmonary chondroid hamartoma with t(3;12)(q27-28;q14-15). Genes Chromosomes Cancer:29:363-366 


\section{Legend to figure}

Figure 1. Sequencing of the PCR product from Case 2 showing the in frame fusion transcript between HMGA2 and NFIB. The fusion point is indicated by an arrow and the stop codon is underlined. 
Table 1 Clinical and cytogenetic data

\section{Case Age/ Size ${ }^{1}$ Site/Depth Karyotype $^{2}$}

No. Sex

1 41/M 20 Arm/Deep 46,XY,ins(9;12)(p24;q15q23)/47,idem,+der(9)ins(9;12)

$2 \quad$ 37/M 23 Thigh/Deep 46,XY,t(9;12)(p22;q15)

${ }^{1}$ Largest diameter in $\mathrm{cm}$.

${ }^{2}$ The karyotype of case 2 has been published [9]. 
Table 2 Primers used for RT-PCR

\begin{tabular}{ll} 
Name $^{1}$ & Sequence (5’ - 3’) \\
\hline NF41475-001 & GCATCTCCCGGAAAGTGCGTT \\
NF41475-005 & TGGCCGGTAAGATGGGTGTCCT \\
NF41475-006 & TGGACATTGGCGGGTAAGATGG \\
HMG846 F & CCACTTCAGCCCAGGGACAACC \\
HMG876 F & CAGCGCCTCAGAAGAGAGGACG \\
HMG902 F & GCCCCAGGAAGCAGCAGCAAG \\
HMG1037 R & CCATTTCCTAGGTCTGCCTCTTGGC \\
HMG1144 R & AGGTAGAAATCGAACGTTGCGCC \\
\hline
\end{tabular}

${ }^{1}$ Primer orientation where $\mathrm{F}$ denotes forward and $\mathrm{R}$ reverse. 
Table 3 Frequencies of the most common chromosome segments recombining with 12q13-15 in lipomas, pleomorphic adenomas, lung hamartomas and uterine leiomyomas

\begin{tabular}{lcccc}
\hline Segment & Lipoma & Adenoma & Hamartoma & Leiomyoma \\
\hline $1 \mathrm{p} 32-34$ & $8 \%$ & 0 & 0 & $<1 \%$ \\
$2 \mathrm{p} 22-24$ & $5 \%$ & 0 & $1 \%$ & 0 \\
$2 \mathrm{q} 35-37$ & $6 \%$ & 0 & 0 & $3 \%$ \\
$3 q 27-29$ & $20 \%$ & 0 & $8 \%$ & 0 \\
$5 q 33$ & $6 \%$ & $2 \%$ & 0 & 0 \\
$9 \mathrm{p} 22-24$ & $1 \%$ & $10 \%$ & $1 \%$ & $4 \%$ \\
$10 \mathrm{q} 22$ & $2 \%$ & 0 & 0 & $4 \%$ \\
$13 q 12-14$ & $4 \%$ & 0 & $3 \%$ & $61 \%$ \\
$14 q 22-24$ & $1 \%$ & $2 \%$ & $18 \%$ & 0 \\
\hline
\end{tabular}


Exon 4 HMGA2 $\quad$ Exon 8 NFIB

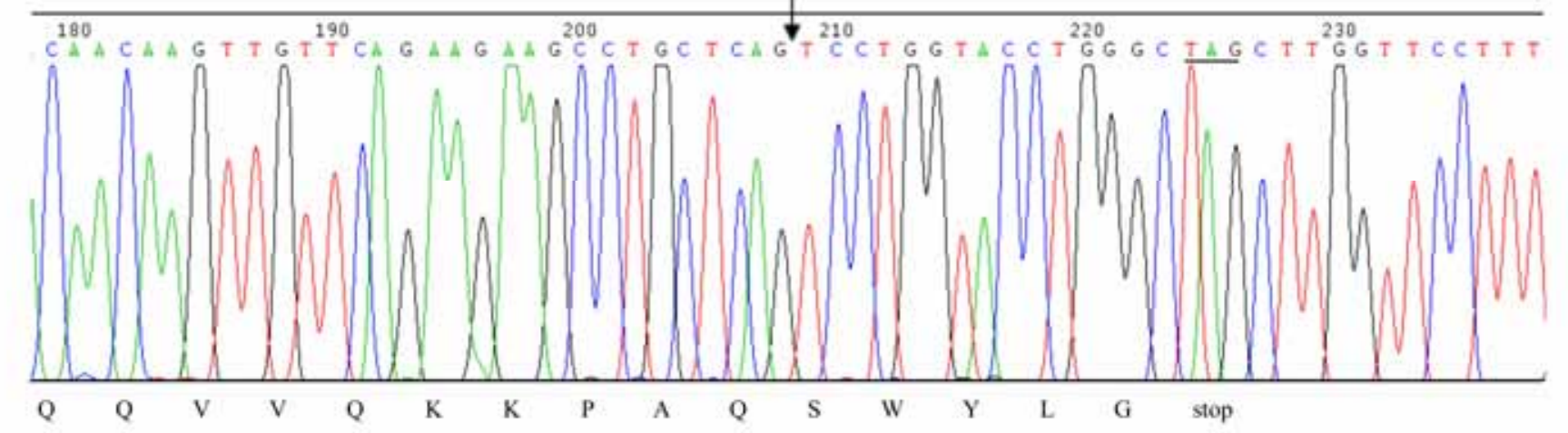

